\title{
Calcified left ventricular aneurysm in a 6-year-old Caucasian boy*
}

\author{
R J SZARNICKI, $M$ R DE LEVAL, J STARK \\ From the Thoracic Unit, The Hospital for Sick Children, Great Ormond Street, London
}

SUMMARY A 6-year-old Caucasian boy presented with a calcified left ventricular aneurysm of unknown aetiology. Aneurysmectomy was carried out uneventfully. A review of the English language papers reveals that this is the first reported case of a calcified left ventricular aneurysm occurring in a Caucasian child.

Left ventricular aneurysms are uncommon in children, and reports are few. Unlike the adult population, where ischaemic heart disease is the most common cause of left ventricular aneurysm, several uncertain theories have been advanced to explain this unusual problem in children. Anomalous coronary arteries, congenital anomalies of cardiac muscle, congenital weakness of the atrioventricular valve ring, trauma, tuberculosis, endarteritis, myocarditis, collagen disease, fungal endocarditis, and endocardial fibroelastosis have all been thought to be associated with the development of left ventricular aneurysms. Since the reports of annular subvalvar left ventricular aneurysms in Nigerians by Robertson and Jackson ${ }^{1}$ and Abrahams and colleagues $^{2}$ a genetic basis has been suggested, since all the early cases reported had occurred in Black patients. Calcification of cardiac aneurysms is exceedingly rare in children, only five cases having been reported to date..$^{3-5}$

We report a calcified left ventricular aneurysm of unknown cause, in a 6-year-old Caucasian boy, who was treated successfully by aneurysmectomy.

\section{Case report}

A 6-year-old Caucasian boy was admitted to The Hospital for Sick Children, Great Ormond Street, for evaluation of persistent cardiomegaly on routine chest $x$-ray film. He was born in the state of

\footnotetext{
$\star$ This work was supported in part by a British Heart Foundation grant.

t Present address: Department of Cardiovascular Surgery, Pacific Medical Center, Clay and Buchanan Streets, PO Box 7999, San Francisco, California 94!20. USA.
}

Washington, and was a product of a full-term pregnancy and uncomplicated delivery. Birthweight was $3175 \mathrm{~g}$. Both parents were Caucasian, 31 years old, and in good health.

A pyloromyotomy was performed at 2 weeks of age, with an uneventful recovery. At 4 years of age he had chicken-pox and at 5 years he underwent repair of an undescended testicle. All immunisations were up to date.

Table Preoperative catheterisation data

\begin{tabular}{lcl}
\hline Site & Pressures $(\mathrm{mmHg})$ & 5 \\
\cline { 2 - 3 } PCW & & \\
RV & $16 / 6$ & \\
LV & $80 / 5$ & $\overline{12}$ \\
PA & $16 / 8$ & $\overline{70}$ \\
Ao & $80 / 70$ & \\
\hline
\end{tabular}

He was a normal healthy child until 18 months before this admission when he had an upper respiratory tract infection. A chest $x$-ray film at that time disclosed cardiomegaly. Follow-up chest $x$-ray films showed persistent cardiomegaly with the development of a 'lump' on the cardiac silhouette, but calcification was not noted then. The child's family moved to the United Kingdom and were referred to us.

On admission, the child was afebrile and appeared well. The chest was clear to auscultation and percussion; the heart rate was 96 beats a minute and regular. All peripheral pulses were present and normal. The apex was in the fourth intercostal space in the left mid-clavicular line. There was no 
jugular venous distinction. The blood pressure was $90 / 55 \mathrm{mmHg}$. The abdomen was flat and soft and there was no hepatomegaly. There was a wellhealed transverse epigastric scar.

$X$-rays of the chest showed cardiomegaly and suggested a curvilinear density on the posterior aspect of the heart, clearly shown on an overpenetrated film (Fig. a and b). An electrocardiogram showed a small $R$ wave in II and $Q$ waves in III and aVF, compatible with an inferior infarct.

Cardiac catheterisation data are shown in the Table and are essentially normal. The angiocardiograms confirmed the presence of a posterior calcified left ventricular aneurysm with a filling defect at its base. The coronary arteries were normal. The ejection fraction was considered normal as judged by the left ventricular angiogram.

On 15 July 1975, a left ventricular aneurysmectomy was performed on cardiopulmonary bypass. At operation the calcified left ventricular aneurysm was found near the posterior descending branch of the right coronary artery. Fresh thrombus was noted in the aneurysmal sac. The coronary artery distribution was normal. The aneurysm was excised and the ventriculotomy closed in the standard fashion.

His postoperative course was uneventful and he was discharged home nine days after operation. He continues to do well two years later. Chest $x$-ray film now shows a normal cardiac silhouette.

\section{Discussion}

Left ventricular aneurysm in childhood is an unusual problem that has been described by several authors. Aneurysmectomy is the preferred treatment and successful resection has been reported previously $^{7}$ in two children both of whom had developed the aneurysms as a result of ischaemia secondary to an anomalous left coronary artery arising from the pulmonary artery. These children were 4 and 23 months of age, respectively.

Several causes for left ventricular aneurysms in children have been suggested, but in most the aetiology is unknown. ${ }^{8}$ A specific type of left ventricular aneurysm had almost exclusively been described in Black patients from poor socioeconomic groups, principally in equatorial Africa and South America $^{2}{ }^{2}$; a few cases have also been described in North American Blacks and in West Indians. This lesion has been called annular subvalvar left ventricular aneurysm, and is thought to result from congenital maldevelopment of the fibrous architecture of the atrioventricular valve rings. Aortic and mitral regurgitation may coexist in these patients. Thinning of the fibrous tissue in the

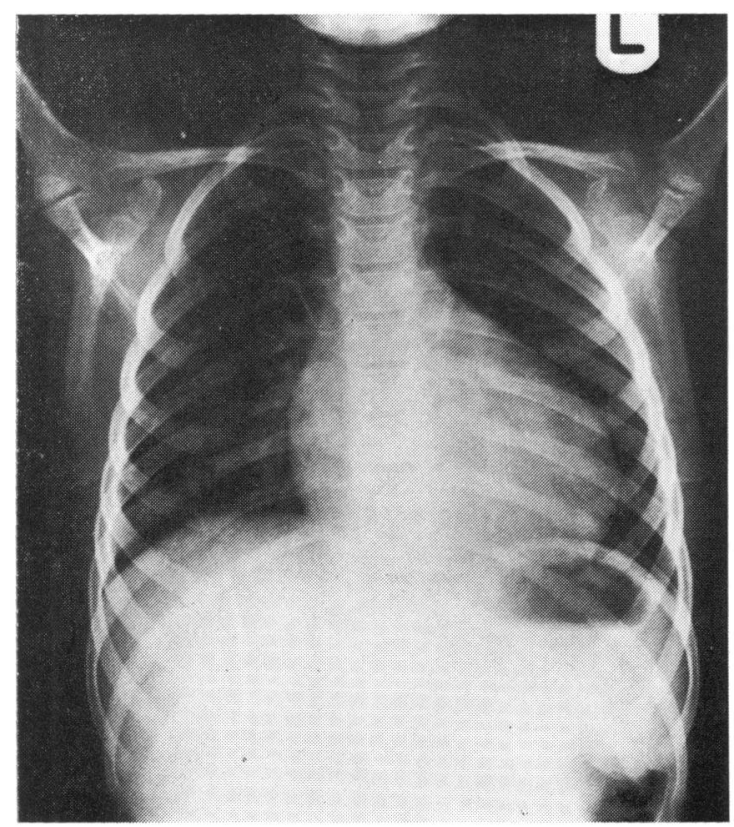

(a)

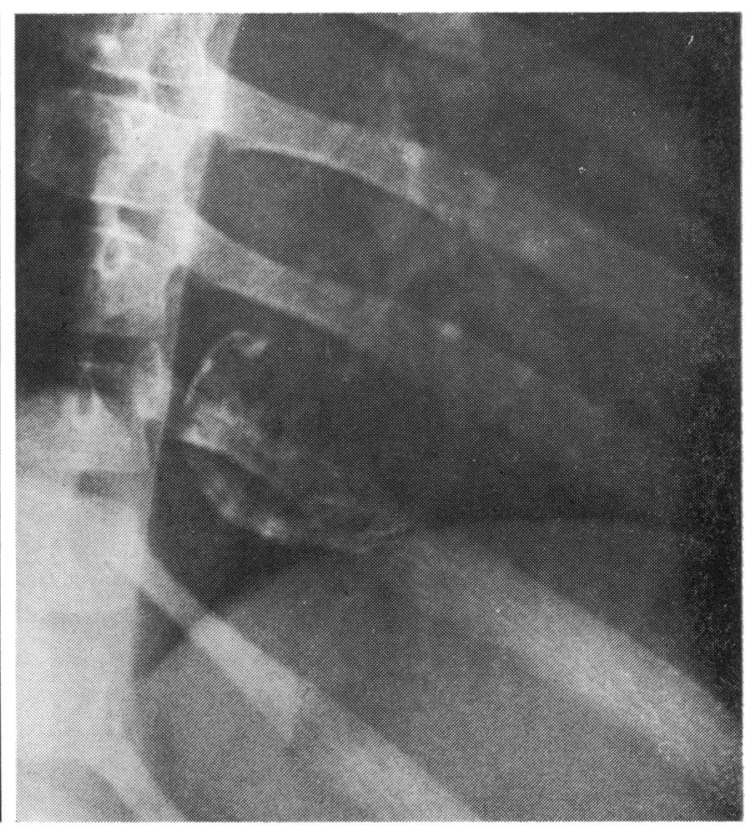

(b)

Fig. Anteroposterior (a) and lateral (b) chest films showing a curvilinear density on the posterior aspect of the heart. 
atrioventricular groove is believed to result from stresses caused by high left ventricular pressures. This process would result in aneurysm formation in the atrioventricular groove extending to the subvalvar region. Few cases of annular subvalvar aneurysm have been reported in Caucasians. ${ }^{8}$ Predisposing factors include trauma, fungal endocarditis after open-heart surgery, subacute bacterial endocarditis, and infective endocarditis, ${ }^{9-11}$ but in one case, an 18-year-old Caucasian, there was no identifiable cause. $^{8}$

Calcification in an aneurysm in children is even more rare, there being only five cases reported in English. It is assumed to be caused by extensive tissue necrosis. All these patients were Black, and in only one of these was the aneurysm of the annular subvalvar type.

\section{References}

'Robertson JH, Jackson JG. Cardiac aneurysms in Nigeria. F Pathol Bacteriol 1960; 80: 101-9.

${ }^{2}$ Abrahams DC, Barton CJ, Cockshott WP, Edington GM, Wearer EJM. Annular subvalvular left ventricular aneurysms. $Q \mathcal{F}$ Med 1962; 31: 345-60.

${ }^{3}$ Papillon J, Bret J, Marion P. Aneurisme de la pointe du coeur chez une enfant. $\mathcal{F}$ Radiol Electrol 1951; 32: 656-7.
${ }^{4}$ Shabetai R, Spitz HR. Calcified left ventricular aneurysm in a child. Am $\mathcal{F}$ Cardiol 1966; 18: 781-4.

${ }^{5}$ Narayan CR, Das JP, Lakshmikanthan C, Munsi SC, Gherian G. Unusual calcification of the heart in children (abstract). Indian Heart f 1969; 21: 138.

'Turina M, Real F, Meier W, Senning A. Left ventricular aneurysmectomy in a 4 month-old infant. $f$ Thorac Cardiovasc Surg 1974; 67: 915-9.

'Flemma RJ, Marx L, Litwin SB, Gallen WJ. Left ventricular aneurysmectomy in a child. Ann Thorac Surg 1975; 19: 457-9.

${ }^{8}$ Pocock WA, Cockshott WP, Ball PJA, Steiner RE. Left ventricular aneurysms of uncertain aetiology. $\mathrm{Br}$ Heart $\mathcal{f}$ 1965; 27: 184-92.

${ }^{\circ}$ Chesler E, Tucker RBK, Barlow JB. Subvalvular and apical left ventricular aneurysms in the Bantu as a source of systemic emboli. Circulation 1974; 35: 115662.

${ }^{10}$ Symbas PN, Ware RE, Belenkie I, Nutter DO. Traumatic biventricular pseudoaneurysm of the heart with ventricular septal defect. I Thorac Cardiovasc Surg 1972; 64: 647-51.

${ }^{11}$ Costa Guimaraes A, Santos Filho A, Pericles Esteves J, et al. Annular subvalvular left aneurysm in Bahia, Brazil. Br Heart $\mathcal{F}$ 1976; 38: 1080-8.

Requests for reprints to $\mathrm{Mr} M \mathrm{R}$ de Leval, Thoracic Unit, The Hospital for Sick Children, Great Ormond Street, London WC1N 3JH. 